\title{
A multicentre study of air pollution exposure and childhood asthma prevalence: the ESCAPE project
}

\author{
Anna Mölter, Angela Simpson, Dietrich Berdel, Bert Brunekreef, \\ Adnan Custovic, Josef Cyrys, Johan de Jongste, Frank de Vocht, Elaine Fuertes, \\ Ulrike Gehring, Olena Gruzieva, Joachim Heinrich, Gerard Hoek, \\ Barbara Hoffmann, Claudia Klümper, Michal Korek, Thomas A.J. Kuhlbusch, \\ Sarah Lindley, Dirkje Postma, Christina Tischer, Alet Wijga, Göran Pershagen \\ and Raymond Agius
}

Affiliation: For a list of the authors' affiliations see the Acknowledgements section.

Correspondence: Anna Mölter, Dept of Environmental and Radiological Health Sciences, Colorado State University, 1681 Campus Delivery, Colorado State University, Fort Collins, C0 80523-1681, USA. E-mail: anna.molter@colostate.edu

ABSTRACT The aim of this study was to determine the effect of six traffic-related air pollution metrics (nitrogen dioxide, nitrogen oxides, particulate matter with an aerodynamic diameter $<10 \mu \mathrm{m}$ (PM10), PM2.5, coarse particulate matter and PM2.5 absorbance) on childhood asthma and wheeze prevalence in five European birth cohorts: MAAS (England, UK), BAMSE (Sweden), PIAMA (the Netherlands), GINI and LISA (both Germany, divided into north and south areas).

Land-use regression models were developed for each study area and used to estimate outdoor air pollution exposure at the home address of each child. Information on asthma and current wheeze prevalence at the ages of 4-5 and 8-10 years was collected using validated questionnaires. Multiple logistic regression was used to analyse the association between pollutant exposure and asthma within each cohort. Random-effects meta-analyses were used to combine effect estimates from individual cohorts.

The meta-analyses showed no significant association between asthma prevalence and air pollution exposure (e.g. adjusted OR $(95 \% \mathrm{CI})$ for asthma at age 8-10 years and exposure at the birth address $(\mathrm{n}=10377): 1.10(0.81-1.49)$ per $10 \mu \mathrm{g} \cdot \mathrm{m}^{-3}$ nitrogen dioxide; $0.88(0.63-1.24)$ per $10 \mu \mathrm{g} \cdot \mathrm{m}^{-3} \mathrm{PM} 10 ; 1.23$ $(0.78-1.95)$ per $\left.5 \mu \mathrm{g} \cdot \mathrm{m}^{-3} \mathrm{PM} 2.5\right)$. This result was consistently found in initial crude models, adjusted models and further sensitivity analyses.

This study found no significant association between air pollution exposure and childhood asthma prevalence in five European birth cohorts.

@ERSpublications

No significant association between air pollution and childhood asthma prevalence in five European birth cohorts http://ow.ly/Cdbba

For editorial comments see Eur Respir J 2015; 45: 589-591 [DOI: 10.1183/09031936.00008415].

This article has supplementary material available from erj.ersjournals.com

Received: May 062014 | Accepted after revision: Sept 132014 | First published online: Oct 162014

Conflict of interest: Disclosures can be found alongside the online version of this article at erj.ersjournals.com

Copyright OERS 2015 


\section{Introduction}

Air pollution exposure is widely recognised as having a range of health effects, including increasing the frequency of asthma attacks in asthmatic children and adults [1]. Asthma is the most common chronic disease in children worldwide and epidemiological information can be of great value in understanding how to reduce the burden of this condition. This is especially important when the putative agent is as ubiquitous as traffic-related air pollution, yet is at the same time potentially responsive to public policy changes. However, it is still unclear whether long-term exposure to air pollution affects asthma prevalence (as distinct from exacerbations) in children. Published studies show heterogeneous results [2-13]. These apparent discrepancies may arise from differences in study design, such as case definitions [14] or exposure assessment $[15,16]$. The European Study of Cohorts for Air Pollution Effects (ESCAPE) is a project funded by the European Union to investigate health effects of long-term exposure to air pollution in the general population. ESCAPE is the first study of its kind to use a harmonised approach to assess exposure across Europe using identical equipment and following standardised protocols [17-20].

The aim of this study was to analyse the association between the prevalence of childhood asthma or current wheeze and six air pollution metrics (nitrogen dioxide, nitrogen oxides $\left(\mathrm{NO}_{x}\right)$, particulate matter with an aerodynamic diameter $<10 \mu \mathrm{m}$ (PM10), PM2.5, coarse particulate matter (i.e. PM10-PM2.5) and PM2.5 absorbance) in five birth cohorts across Europe. We hypothesised that increased exposure during infancy and early childhood increases the prevalence of childhood asthma.

\section{Methods}

\section{Study population}

This analysis included five birth cohort studies: the Manchester Asthma and Allergy Study (MAAS) based in England, UK; the Barn Allergi Miliö Stockholm Epidemiologi (BAMSE) study based in Sweden; the Prevention and Incidence of Asthma and Mite Allergy (PIAMA) study based in the Netherlands; and the German Infant Nutritional Intervention (GINIplus) study and the Lifestyle-Related Factors on the Development of the Immune System and Allergic Disease (LISAplus) study, both based in Germany. Data from the GINIplus and LISAplus cohorts were combined for analytical purposes as they follow almost identical study protocols. However, as exposure was assessed by city, separate analyses were carried for GINI/LISA South (Munich region) and GINI/LISA North (Wesel region).

Each of the above cohorts was designed to study the development of asthma and allergies during childhood [21-24]. An overview of the size, inception and age of each cohort is provided in table 1. At birth, all cohorts were unselected, population-based studies, and all are currently ongoing. Further information on each cohort is provided in the online supplementary material. Ethical approval was granted by the institutional review board or local research ethics committee of each cohort study. Written informed consent was obtained from parents or legal guardians of all participants.

\section{Health outcomes}

All cohorts used questionnaires based on the International Study of Asthma and Allergies in Childhood (ISAAC; a multinational collaboration, which established a standardised methodology to collect epidemiological data on asthma and allergies (http://isaac.auckland.ac.nz)) [25], to collect data on asthma

Support statement: The research leading to these results has received funding from the European Community Seventh Framework Programme (FP7/2007-2011) under grant agreement number 211250. MAAS was supported by Asthma UK, the J.P. Moulton Charitable Foundation and the UK Medical Research Council (grants G0601361 and MR/ K002449/1). In addition, we acknowledge support from the North West Lung Centre Charity. The GINIplus study was mainly supported for the first 3 years by the Federal Ministry for Education, Science, Research and Technology (interventional arm) and Helmholtz Zentrum Munich (formerly GSF) (observational arm). The 4-, 6- and 10-year follow-up examinations of the GINIplus study were covered from the respective budgets of the five study centres (Helmholtz Zentrum Munich, Marien-Hospital Wesel, LMU Munich and TU Munich, and from 6 years onwards, also from IUF, Leibniz Research Institute for Environmental Medicine) and a grant from the Federal Ministry for Environment (IUF, FKZ 20462296). The LISAplus study was mainly supported by grants from the Federal Ministry for Education, Science, Research and Technology, and in addition from Helmholtz Zentrum Munich, Helmholtz Centre for Environmental Research - UFZ, Leipzig, Marien-Hospital Wesel and Pediatric Practice, Bad Honnef for the first 2 years. The 4-, 6- and 10-year follow-up examinations of the LISAplus study were covered from the respective budgets of the involved partners (Helmholtz Zentrum Munich, Helmholtz Centre for Environmental Research - UFZ, Leipzig, Marien-Hospital Wesel, Pediatric Practice, Bad Honnef, and IUF - Leibniz-Research Institute for Environmental Medicine) and in addition by a grant from the Federal Ministry for Environment (IUF, FKZ 20462296). The BAMSE study was supported by the Swedish Heart-Lung Foundation, the Konsul Th.C. Bergh Foundation, Stockholm County Council, the Swedish Asthma and Allergy Association Research Foundation, the Swedish Foundation for Health Care Sciences and Allergy Research and the Swedish Environmental Protection Agency. The PIAMA study is supported by the Netherlands Organization for Health Research and Development; the Netherlands Organization for Scientific Research; the Netherlands Asthma Fund; the Netherlands Ministry of Spatial Planning, Housing, and the Environment; and the Netherlands Ministry of Health, Welfare, and Sport. 
TABLE 1 Cohort studies included in meta-analysis

\begin{tabular}{|c|c|c|c|c|}
\hline Cohort & Study area/country & Recruitment & Age at follow-up years & Subjects at birth $\mathrm{n}$ \\
\hline PIAMA & $\begin{array}{l}\text { North, west and central } \\
\text { areas, the Netherlands }\end{array}$ & 1996-1997 & Annually, birth until age $8,11,14$ & 3963 \\
\hline
\end{tabular}

MAAS: Manchester Asthma and Allergy Study; BAMSE: Barn Allergi Miliö Stockholm Epidemiologi; PIAMA: Prevention and Incidence of Asthma and Mite Allergy; GINI: German Infant Nutritional Intervention; LISA: Lifestyle-Related Factors on the Development of the Immune System and Allergic Disease. " : LISA only; ${ }^{\uparrow}$ : GINI only.

and current wheeze at the ages of 4 years (age 5 years in MAAS) and 8 years (age 10 years in GINI/LISA). For the purpose of this analysis, the Global Allergy and Asthma European Network $\left(\mathrm{GA}^{2} \mathrm{LEN}\right)$ definition of asthma [26, 27] was used, which is based on at least two positive answers to the following three questions. 1) Has a doctor ever diagnosed asthma in your child? 2) Has your child had wheezing or whistling in the chest in the last 12 months? 3) Has your child been prescribed asthma medication during the last 12 months? Current wheeze was defined as wheezing or whistling in the chest during the last 12 months.

\section{Exposure assessment}

Exposures to commonly used markers of urban air pollution $\left(\mathrm{NO}_{2}, \mathrm{NO}_{x}, \mathrm{PM} 10, \mathrm{PM} 2.5\right.$, coarse particulate matter and PM2.5 absorbance) at each child's birth address, their address at age 4 years (age 5 years address in MAAS; age 4 years addresses not available in GINI/LISA) and age 8 years (age 10 years address in GINI/LISA) were estimated using land-use regression (LUR) models. LUR is a commonly used method in air pollution epidemiology, which analyses the relationship between measured pollutant concentrations and surrounding land use characteristics (e.g. industrial activity or traffic density). Multiple linear regression is used to identify land use variables that best predict pollutant concentrations and these will form the final model. The final LUR model can be used to predict pollutant concentrations at any location within the study area.

LUR models were specifically developed for the ESCAPE study and used a standardised protocol [28]. The pollutant concentrations used to develop these models were measured at 40 sites (20 for particulate matter metrics) in each study area during three 2-week-long measurement campaigns in different seasons in 2009 using the same methodology and equipment $[18,20]$. The development of the LUR models has been described in detail elsewhere $[17,19]$. The LUR models were applied to the birth, age 4 or 5 years and age



FIGURE 1 Prevalence of asthma and current wheeze. Data are presented as n/N. MAAS: Manchester Asthma and Allergy Study; BAMSE: Barn Allergi Miliö Stockholm Epidemiologi; PIAMA: Prevention and Incidence of Asthma and Mite Allergy; GINI: German Infant Nutritional Intervention; LISA: Lifestyle-Related Factors on the Development of the Immune System and Allergic Disease. 
8 or 10 years addresses of the children to allow for children moving home while attending primary school. However, these exposure estimates did not allow for changes over time in annual mean concentrations. Therefore, as a sensitivity analysis, exposure estimates at the birth addresses were back-extrapolated over time [29]. For the back-extrapolation data from urban background monitors in routine monitoring networks on measured $\mathrm{NO}_{2}, \mathrm{NO}_{x}$ and PM10 concentrations were collected in each study area. For each study area, we calculated the difference and ratio between concentrations measured in 2009 and during the year of interest for the cohort. The resulting differences and ratios were applied to the modelled exposure estimates at the birth addresses of the cohort participants. Further details are available from [29, 30].

In addition to modelled pollutant concentrations, two traffic metrics (traffic intensity on the nearest street and traffic intensity on major roads within a $100-\mathrm{m}$ radius) were also used as exposure variables. These traffic metrics were used in combination with an estimate of background $\mathrm{NO}_{2}$ concentrations derived from a separate background LUR model. The background LUR model was developed using only regional and urban background sites and background predictor variables [28].

\section{Statistical analysis}

Each cohort used logistic regression to analyse the associations between asthma or current wheeze prevalence at age $4 / 5$ or 8/10 years, and air pollution exposure at the birth address, age 4/5 years address or age $8 / 10$ years address. Logistic regression is the most commonly used method to analyse associations between a binary outcome variable and exposure variables [31]. Logistic regression analyses were carried out in SAS 9.1 (SAS Institute, Cary, NC, USA), STATA 11.1 (StataCorp, College Station, TX, USA) and SPSS 20 (IBM Corp., Armonk, NY, USA).

All cohorts followed the same protocol. Based on knowledge from previous studies, a set of potential confounding variables was selected a priori to be used by all cohorts. Initially, "crude models" (model 1) of the outcome and exposure were analysed, which only adjusted for the sex and age of the child. Subsequently, adjusted models (model 2) were analysed, which adjusted for the potential confounding variables selected a priori (table S2). Further analyses included the addition of the area-level socioeconomic status or the addition of birth weight to the adjusted model. Sensitivity analyses using back-extrapolated exposure data (as described earlier), and stratified analyses by sex and in children who

TABLE 2 Characteristics of study populations at birth



Data are presented as $\mathrm{n} / \mathrm{N}(\%)$ or mean \pm SD. MAAS: Manchester Asthma and Allergy Study; BAMSE: Barn Allergi Miliö Stockholm Epidemiologi; PIAMA: Prevention and Incidence of Asthma and Mite Allergy; GINI: German Infant Nutritional Intervention; LISA: Lifestyle-Related Factors on the Development of the Immune System and Allergic Disease. "\# during the first 2 years of life. 
TABLE 3 Modelled air pollution exposure in each cohort

\begin{tabular}{|c|c|c|c|c|c|c|}
\hline Pollutant & $\begin{array}{l}\text { Age }^{\#} \\
\text { years }\end{array}$ & MAAS & BAMSE & PIAMA & GINI/LISA South & GINI/LISA North \\
\hline \multirow[t]{3}{*}{$\mathrm{NO}_{2} \mu \mathrm{g} \cdot \mathrm{m}^{-3}$} & Birth & $22.9 \pm 2.0(16.0-30.4)$ & $14.0 \pm 5.4(6.0-33.0)$ & $23.2 \pm 6.7(9.2-55.3)$ & $22.0 \pm 6.2(11.5-61.1)$ & $23.9 \pm 3.6(19.6-62.8)$ \\
\hline & $4 / 5$ & $22.7 \pm 2.0(16.0-29.1)$ & $12.0 \pm 5.0(6.0-32.9)$ & $22.3 \pm 6.3(9.2-55.3)$ & NA & NA \\
\hline & $8 / 10$ & $22.7 \pm 2.0(16.0-30.9)$ & $11.9 \pm 5.0(6.0-38.5)$ & $22.0 \pm 6.1(9.2-53.4)$ & $19.8 \pm 5.1(11.5-56.9)$ & $23.7 \pm 3.5(19.7-61.4)$ \\
\hline \multirow[t]{3}{*}{$\mathrm{NO}_{x} \mu \mathrm{g} \cdot \mathrm{m}^{-3}$} & Birth & $39.0 \pm 4.8(26.1-77.8)$ & $25.5 \pm 11.9(11.8-86.3)$ & $34.3 \pm 11.6(16.5-98.9)$ & $36.6 \pm 10.5(19.7-121.4)$ & $35.0 \pm 9.8(23.8-147.6)$ \\
\hline & $4 / 5$ & $38.6 \pm 4.7(26.1-77.8)$ & $21.3 \pm 11.0(11.8-84.3)$ & $32.8 \pm 10.7(16.4-100.1)$ & NA & NA \\
\hline & $8 / 10$ & $38.7 \pm 5.0(26.4-77.8)$ & $21.1 \pm 10.9(11.8-84.9)$ & $32.2 \pm 10.3(16.5-100.1)$ & $33.8 \pm 8.4(19.7-110.0)$ & $34.7 \pm 9.4(23.9-43.7)$ \\
\hline \multirow[t]{3}{*}{ PM2.5 abs. ${ }^{\pi} \times 10^{-5} \mathrm{~m}^{-1}$} & Birth & $1.2 \pm 0.2(0.7-2.0)$ & $0.7 \pm 0.2(0.4-1.3)$ & $1.2 \pm 0.3(0.9-3.0)$ & $1.7 \pm 0.2(1.3-3.6)$ & $1.2 \pm 0.2(0.9-3.1)$ \\
\hline & $4 / 5$ & $1.1 \pm 0.16(0.7-1.9)$ & $0.6 \pm 0.2(0.4-1.3)$ & $1.2 \pm 0.23(0.9-2.8)$ & NA & NA \\
\hline & $8 / 10$ & $1.1 \pm 0.16(0.7-1.9)$ & $0.6 \pm 0.2(0.4-1.8)$ & $1.2 \pm 0.2(0.9-2.3)$ & $1.65 \pm 0.18(1.3-3.5)$ & $1.2 \pm 0.2(1.0-3.4)$ \\
\hline \multirow[t]{3}{*}{$\mathrm{PM} 2.5 \mu \mathrm{g} \cdot \mathrm{m}^{-3}$} & Birth & $9.4 \pm 0.2(9.4-11.0)$ & $7.8 \pm 1.2(4.2-11.4)$ & $16.4 \pm 0.7(15.3-20.9)$ & $13.4 \pm 1.0(10.6-18.3)$ & $17.4 \pm 0.7(15.8-21.5)$ \\
\hline & $4 / 5$ & $9.4 \pm 0.2(9.4-10.8)$ & $7.4 \pm 1.3(4.2-11.0)$ & $16.4 \pm 0.7(15.3-20.7)$ & NA & NA \\
\hline & $8 / 10$ & $9.4 \pm 0.1(9.4-10.8)$ & $7.4 \pm 1.3(4.2-17.3)$ & $16.3 \pm 0.7(14.9-20.7)$ & $13.3 \pm 0.9(10.7-18.8)$ & $17.4 \pm 0.7(15.8-21.7)$ \\
\hline \multirow[t]{3}{*}{$\mathrm{PM} 10 \mu \mathrm{g} \cdot \mathrm{m}^{-3}$} & Birth & $17.2 \pm 0.9(12.6-22.7)$ & $15.7 \pm 3.9(6.0-30.9)$ & $25.0 \pm 1.2(23.7-32.7)$ & $20.4 \pm 2.4(14.8-34.3)$ & $25.5 \pm 1.2(23.9-33.5)$ \\
\hline & $4 / 5$ & $17.1 \pm 0.9(14.0-22.6)$ & $15.3 \pm 3.5(6.0-30.9)$ & $24.8 \pm 1.0(23.7-31.3)$ & NA & NA \\
\hline & $8 / 10$ & $17.1 \pm 0.8(12.6-22.5)$ & $15.4 \pm 3.6(6.0-45.7)$ & $24.7 \pm 1.0(23.7-30.2)$ & $20.0 \pm 2.3(14.8-33.4)$ & $25.5 \pm 1.3(23.9-33.3)$ \\
\hline \multirow[t]{3}{*}{ Coarse $\mathrm{PM} \mu \mathrm{g} \cdot \mathrm{m}^{-3}$} & Birth & $7.0 \pm 0.9(5.0-11.5)$ & $7.9 \pm 3.0(0.7-20.2)$ & $8.4 \pm 0.9(7.6-11.1)$ & $6.8 \pm 1.5(4.1-16.0)$ & $8.5 \pm 0.8(2.0-13.8)$ \\
\hline & $4 / 5$ & $7.0 \pm 0.8(5.0-11.5)$ & $7.6 \pm 2.7(0.7-20.2)$ & $8.3 \pm 0.7(7.6-14.0)$ & NA & NA \\
\hline & $8 / 10$ & $7.0 \pm 0.8(5.1-11.5)$ & $7.6 \pm 2.8(0.7-27.3)$ & $8.2 \pm 0.7(7.6-11.9)$ & $6.3 \pm 1.3(4.1-15.4)$ & $8.4 \pm 0.7(2.1-14.5)$ \\
\hline \multirow{3}{*}{$\begin{array}{l}\text { Traffic int. on nearest } \\
\text { road veh.day }{ }^{-1}\end{array}$} & Birth & $500 \pm 0(500-29590)$ & $500 \pm 1450(122-52020)$ & $218 \pm 447(0-54610)$ & $500 \pm 0(500-134000)$ & $500 \pm 0(500-38944)$ \\
\hline & $4 / 5$ & $500 \pm 0(500-32861)$ & $500 \pm 0(500-50920)$ & $199 \pm 367(0-54610)$ & NA & NA \\
\hline & $8 / 10$ & $500 \pm 0(500-49466)$ & $500 \pm 127(122-50920)$ & $187 \pm 335(0-46120)$ & $500 \pm 0(0-134000)$ & $500 \pm 0(500-21258)$ \\
\hline \multirow{3}{*}{$\begin{array}{l}\text { Traffic int. on major } \\
\text { roads within } 100-m \\
\text { radius veh.day }{ }^{-1} \cdot m^{-1}\end{array}$} & Birth & $0 \pm 0(0-63463780)$ & $0 \pm 1594316(0-26000000)$ & $0 \pm 0(0-23498579)$ & $0 \pm 0(0-52741068)$ & $0 \pm 0\left(\begin{array}{llll}0-11 & 178 & 024\end{array}\right)$ \\
\hline & $4 / 5$ & $0 \pm 0(0-63463780)$ & $0 \pm 858865(0-7141670)$ & $0 \pm 0(0-20998484)$ & NA & NA \\
\hline & $8 / 10$ & $0 \pm 0(0-63463780)$ & $0 \pm 912730(0-6948560)$ & $0 \pm 0(0-14669857)$ & $0 \pm 0(0-542974787)$ & $0 \pm 0(0-16904875)$ \\
\hline
\end{tabular}

Data are presented as mean \pm SD (range). MAAS: Manchester Asthma and Allergy Study; BAMSE: Barn Allergi Miliö Stockholm Epidemiologi; PIAMA: Prevention and Incidence of Asthma and Mite Allergy; GINI: German Infant Nutritional Intervention; LISA: Lifestyle-Related Factors on the Development of the Immune System and Allergic Disease; NO I $_{x}$ nitrogen oxides; PM2.5: particulate matter with an aerodynamic diameter <2.5 $\mu \mathrm{m}$; abs.: absorbance; PM10: particulate matter with an aerodynamic diameter <10 $\mu$ m; PM: particulate matter; int.: intensity; veh: vehicles; NA: not available. \#: at age 4/5 years, restricted to children for whom asthma outcome was available at age $4 / 5$ years; at age $8 / 10$ years, restricted to children for whom asthma outcome was available at age $8 / 10$ years. ": PM10 abs. was measured but not further used in LUR modelling and epidemiological analyses because earlier work has shown that PM10 and PM2.5 absorbance are almost identical [34, 35]. 
TABLE 4 Results of meta-analyses of effect estimates derived from logistic regression models of asthma and pollutant exposure

\begin{tabular}{|c|c|c|c|c|c|c|c|c|c|c|c|c|}
\hline \multirow[t]{2}{*}{ Outcome } & \multirow[t]{2}{*}{ Exposure } & \multirow[t]{2}{*}{ Address } & \multicolumn{5}{|c|}{ Crude model $^{\#}$} & \multicolumn{5}{|c|}{ Adjusted model ${ }^{\pi}$} \\
\hline & & & OR $(95 \% \mathrm{CI})$ & p-value & $I^{2} \%$ & phet & Subjects $n$ & OR $(95 \% \mathrm{Cl})$ & p-value & $I^{2} \%$ & phet & Subjects $n$ \\
\hline \multirow{12}{*}{$\begin{array}{l}\text { Asthma at } \\
\text { age } 4 / 5 \text { years }\end{array}$} & $\mathrm{NO}_{2}\left(10 \mu \mathrm{g} \cdot \mathrm{m}^{-3}\right)$ & \multirow[t]{6}{*}{ Birth } & $0.94(0.68-1.30)$ & 0.72 & 81.6 & $<0.001$ & \multirow[t]{6}{*}{13186} & $1.17(0.84-1.62)$ & 0.35 & 67.2 & 0.016 & \multirow[t]{6}{*}{11555} \\
\hline & $\mathrm{NO}_{x}\left(20 \mu \mathrm{g} \cdot \mathrm{m}^{-3}\right)$ & & $0.99(0.74-1.32)$ & 0.92 & 77.8 & 0.001 & & $1.10(0.86-1.40)$ & 0.44 & 52.8 & 0.08 & \\
\hline & $\mathrm{PM} 10\left(10 \mu \mathrm{g} \cdot \mathrm{m}^{-3}\right)$ & & $0.76(0.52-1.11)$ & 0.16 & 21.1 & 0.28 & & $0.96(0.65-1.40)$ & 0.82 & 13.7 & 0.33 & \\
\hline & $\mathrm{PM}_{2.5}\left(5 \mu \mathrm{g} \cdot \mathrm{m}^{-3}\right)$ & & $0.78(0.50-1.20)$ & 0.26 & 22.6 & 0.27 & & $1.34(0.89-2.02)$ & 0.16 & 0.0 & 0.66 & \\
\hline & PM2.5 absorbance $\left(10^{-5} \mathrm{~m}^{-1}\right)$ & & $0.95(0.45-2.03)$ & 0.90 & 81.7 & $<0.001$ & & $1.33(0.80-2.21)$ & 0.27 & 33.6 & 0.20 & \\
\hline & Coarse PM $\left(5 \mu \mathrm{g} \cdot \mathrm{m}^{-3}\right)$ & & $0.89(0.61-1.30)$ & 0.55 & 45.2 & 0.12 & & $0.97(0.66-1.43)$ & 0.89 & 35.4 & 0.19 & \\
\hline & $\mathrm{NO}_{2}\left(10 \mu \mathrm{g} \cdot \mathrm{m}^{-3}\right)$ & \multirow[t]{6}{*}{ Age $4 / 5$ years } & $1.09(0.74-1.62)$ & 0.65 & 82.7 & 0.003 & \multirow[t]{6}{*}{7664} & $1.13(0.89-1.43)$ & 0.33 & 39.7 & 0.19 & \multirow[t]{6}{*}{7096} \\
\hline & $\mathrm{NO}_{x}\left(20 \mu \mathrm{g} \cdot \mathrm{m}^{-3}\right)$ & & $1.10(0.77-1.57)$ & 0.59 & 79.4 & 0.008 & & $1.08(0.92-1.26)$ & 0.34 & 0.0 & 0.41 & \\
\hline & $\mathrm{PM} 10\left(10 \mu \mathrm{g} \cdot \mathrm{m}^{-3}\right)$ & & $0.74(0.57-0.97)$ & 0.03 & 0.0 & 0.69 & & $0.93(0.68-1.26)$ & 0.62 & 0.0 & 0.46 & \\
\hline & $\mathrm{PM}_{2.5}\left(5 \mu \mathrm{g} \cdot \mathrm{m}^{-3}\right)$ & & $0.90(0.58-1.41)$ & 0.66 & 12.9 & 0.32 & & $1.14(0.76-1.71)$ & 0.51 & 0.0 & 0.66 & \\
\hline & PM2.5 absorbance $\left(10^{-5} \mathrm{~m}^{-1}\right)$ & & $1.30(0.45-3.77)$ & 0.63 & 87.2 & $<0.001$ & & $1.31(0.76-2.28)$ & 0.33 & 32.2 & 0.23 & \\
\hline & Coarse PM $\left(5 \mu \mathrm{g} \cdot \mathrm{m}^{-3}\right)$ & & $1.32(0.64-2.73)$ & 0.45 & 74.1 & 0.021 & & $1.05(0.77-1.43)$ & 0.74 & 12.2 & 0.32 & \\
\hline \multirow{12}{*}{$\begin{array}{l}\text { Asthma at } \\
\text { age } 8 / 10 \text { years }\end{array}$} & $\mathrm{NO}_{2}\left(10 \mu \mathrm{g} \cdot \mathrm{m}^{-3}\right)$ & \multirow[t]{6}{*}{ Birth } & $1.05(0.75-1.46)$ & 0.79 & 80.2 & $<0.001$ & \multirow[t]{6}{*}{11567} & $1.10(0.81-1.49)$ & 0.54 & 57.9 & 0.050 & \multirow[t]{6}{*}{10377} \\
\hline & $\mathrm{NO}_{x}\left(20 \mu \mathrm{g} \cdot \mathrm{m}^{-3}\right)$ & & $1.05(0.77-1.41)$ & 0.77 & 78.4 & $<0.001$ & & $1.07(0.86-1.33)$ & 0.54 & 35.2 & 0.19 & \\
\hline & $\mathrm{PM} 10\left(10 \mu \mathrm{g} \cdot \mathrm{m}^{-3}\right)$ & & $1.20(0.64-2.24)$ & 0.58 & 55.5 & 0.06 & & $0.88(0.63-1.24)$ & 0.47 & 2.6 & 0.39 & \\
\hline & PM2.5 $\left(5 \mu \mathrm{g} \cdot \mathrm{m}^{-3}\right)$ & & $1.13(0.61-2.09)$ & 0.70 & 46.4 & 0.11 & & $1.23(0.78-1.95)$ & 0.38 & 0.0 & 0.92 & \\
\hline & PM2.5 absorbance $\left(10^{-5} \mathrm{~m}^{-1}\right)$ & & $1.03(0.55-1.95)$ & 0.92 & 69.4 & 0.011 & & $1.25(0.84-1.86)$ & 0.27 & 0.0 & 0.59 & \\
\hline & Coarse PM $\left(5 \mu \mathrm{g} \cdot \mathrm{m}^{-3}\right)$ & & $1.08(0.69-1.70)$ & 0.73 & 54.1 & 0.07 & & $1.10(0.72-1.69)$ & 0.65 & 39.4 & 0.16 & \\
\hline & $\mathrm{NO}_{2}\left(10 \mu \mathrm{g} \cdot \mathrm{m}^{-3}\right)$ & \multirow[t]{6}{*}{ Age $4 / 5$ years } & $1.13(0.85-1.50)$ & 0.39 & 66.4 & 0.018 & \multirow[t]{6}{*}{10944} & $1.11(0.95-1.31)$ & 0.20 & 0.0 & 0.68 & \multirow[t]{6}{*}{9823} \\
\hline & $\mathrm{NO}_{x}\left(20 \mu \mathrm{g} \cdot \mathrm{m}^{-3}\right)$ & & $1.05(0.86-1.28)$ & 0.61 & 38.2 & 0.17 & & $1.06(0.90-1.25)$ & 0.48 & 0.0 & 0.93 & \\
\hline & $\mathrm{PM} 10\left(10 \mu \mathrm{g} \cdot \mathrm{m}^{-3}\right)$ & & $0.99(0.74-1.31)$ & 0.92 & 0.0 & 0.46 & & $1.09(0.79-1.52)$ & 0.59 & 0.0 & 0.71 & \\
\hline & $\mathrm{PM} 2.5\left(5 \mu \mathrm{g} \cdot \mathrm{m}^{-3}\right)$ & & $1.15(0.58-2.31)$ & 0.69 & 48.6 & 0.10 & & $1.00(0.65-1.52)$ & 0.99 & 0.0 & 0.46 & \\
\hline & PM2.5 absorbance $\left(10^{-5} \mathrm{~m}^{-1}\right)$ & & $0.99(0.60-1.65)$ & 0.98 & 38.7 & 0.16 & & $1.06(0.69-1.62)$ & 0.79 & 0.0 & 0.62 & \\
\hline & Coarse PM $\left(5 \mu \mathrm{g} \cdot \mathrm{m}^{-3}\right)$ & & $1.11(0.79-1.57)$ & 0.56 & 20.5 & 0.28 & & $1.16(0.93-1.44)$ & 0.20 & 0.0 & 0.70 & \\
\hline
\end{tabular}

$\mathrm{I}^{2}$ : inconsistency; phet: $\mathrm{p}$-value for heterogeneity; $\mathrm{NO}_{x}$ : nitrogen oxides; $\mathrm{PM} 10$ : particulate matter with an aerodynamic diameter <10 $\mu \mathrm{m}$; $\mathrm{PM} 2.5$ : particulate matter with an aerodynamic diameter <2.5 $\mu \mathrm{m}$; PM: particulate matter. " : adjusted for sex and age; १: adjusted for sex, age, older siblings, gas cooking, damp or mould, maternal smoking during pregnancy, any smoker living in the home, $>12$ weeks of breastfeeding, day care attendance, parental atopy, personal socioeconomic status, maternal age at birth, dog ownership, cat ownership and region (Barn Allergi Miliö Stockholm Epidemiologi (BAMSE) study only). 


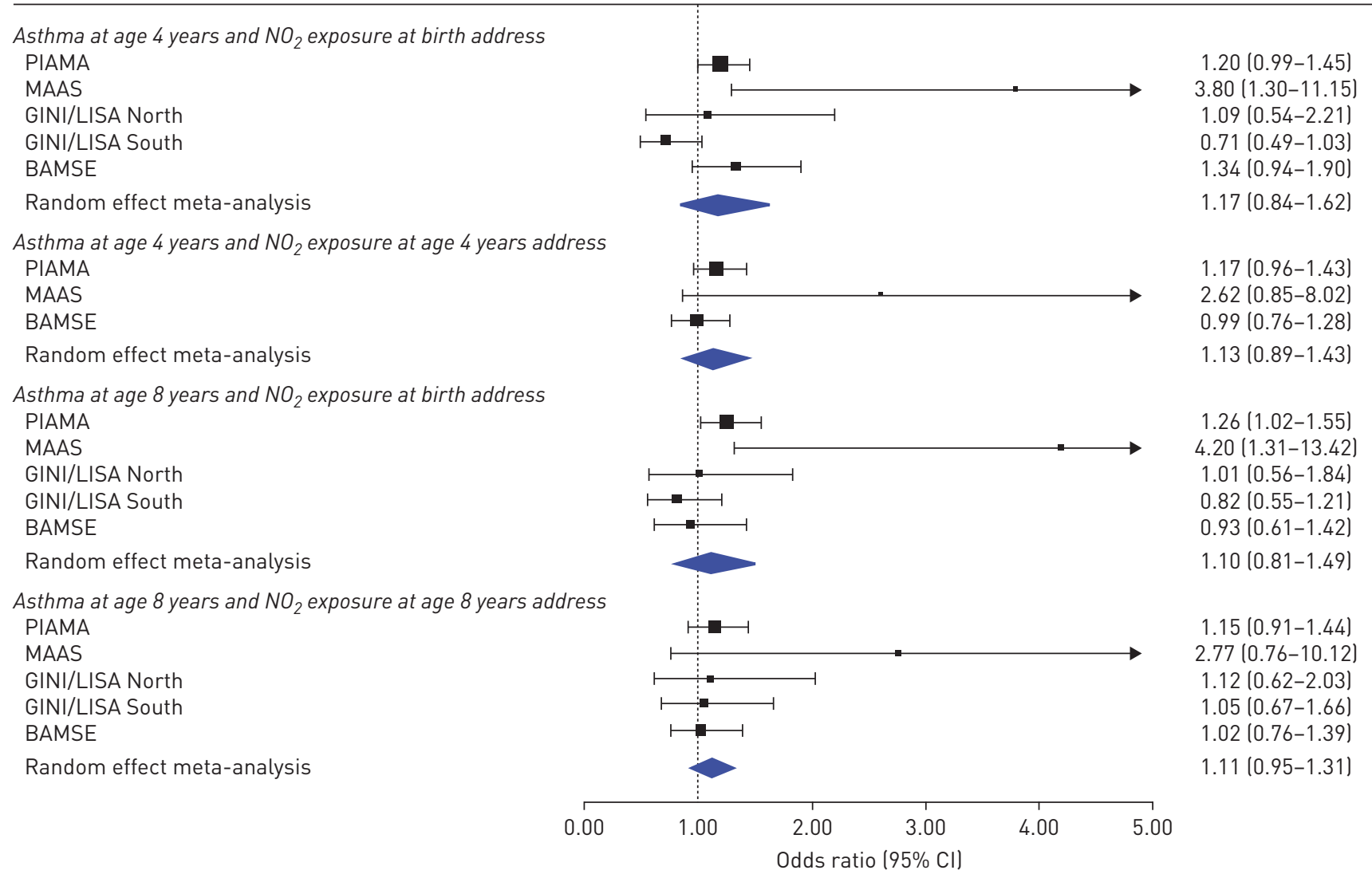

FIGURE 2 Forest plot of the association between asthma at age 4/5 and $8 / 10$ years and nitrogen dioxide exposure at the birth, age 4/5 and age $8 / 10$ years addresses. Associations shown were derived from the adjusted model (model 2). Odds ratios are reported per $10 \mu \mathrm{g} \cdot \mathrm{m}^{-3} \mathrm{NO}_{2}$. PIAMA: Prevention and Incidence of Asthma and Mite Allergy; MAAS: Manchester Asthma and Allergy Study; GINI: German Infant Nutritional Intervention; LISA: Lifestyle-Related Factors on the Development of the Immune System and Allergic Disease; BAMSE: Barn Allergi Miliö Stockholm Epidemiologi.

changed or did not change address were also carried out. Table S2 lists all models and the covariates included in each model.

Multinomial logistic regression was used to analyse the association between nonatopic asthma or atopic asthma at age 8/10 years and air pollution exposure at the birth or age 8/10 years address. Multinomial logistic regression follows the same principles as binary logistic regression but examines associations with categorical outcome variables with more than two levels [31]. Nonatopic, nonasthmatic children were used as the reference category. The statistical analyses were adjusted for the same covariates as the logistic regression models.

Finally, random-effects meta-analyses [32] were carried out in R v2.15.0 [33] to obtain a combined effect estimate from all cohorts. Meta-analysis is a statistical method used to combine results from studies in several study areas into an overall effect estimate [31]. The random-effects method was used to allow for potential heterogeneity between results obtained in different study areas [31]. Odds ratios are reported per $10 \mu \mathrm{g} \cdot \mathrm{m}^{-3} \mathrm{NO}_{2}$, per $20 \mu \mathrm{g} \cdot \mathrm{m}^{-3} \mathrm{NO}_{x}$, per $10 \mu \mathrm{g} \cdot \mathrm{m}^{-3} \mathrm{PM} 10$, per $5 \mu \mathrm{g} \cdot \mathrm{m}^{-3} \mathrm{PM} 2.5$ and per unit PM2.5 absorbance. These exposure increments are used to report findings from all epidemiological studies within ESCAPE and are based on exposure ranges found across all ESCAPE study areas.

\section{Results}

\section{Description of clinical outcomes and potential confounders}

The prevalence of asthma and current wheeze in each cohort is shown in figure 1. The highest prevalence of asthma was found in MAAS, while the lowest prevalence was found in the GINI/LISA cohorts. In the MAAS and BAMSE cohorts, the prevalence of asthma and current wheeze was very similar, while in the GINI/LISA cohorts, the prevalence of current wheeze was higher than that of asthma. Descriptive analyses showing the frequency distributions of covariates in each cohort are provided in table 2. 


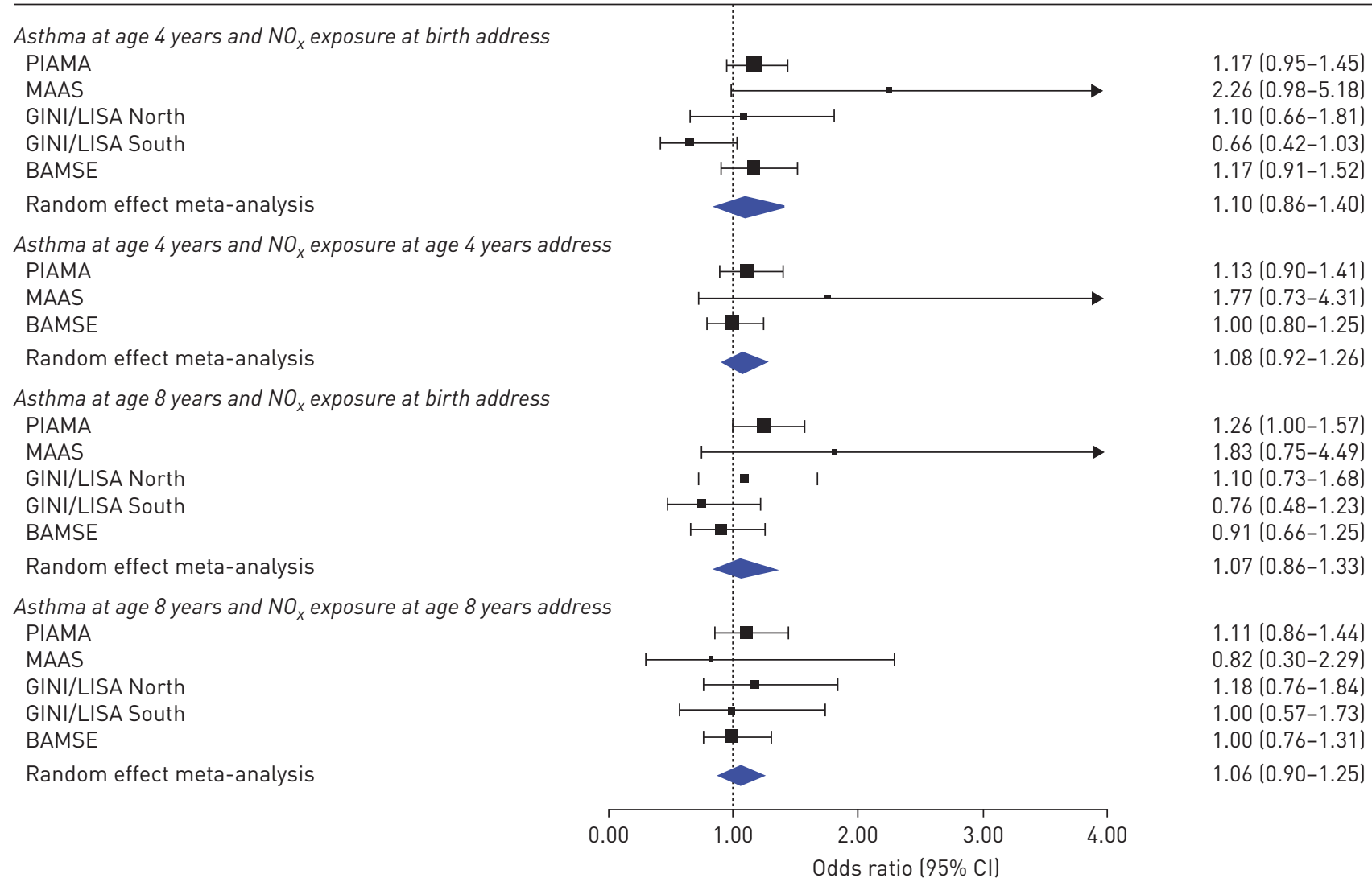

FIGURE 3 Forest plot of the association between asthma at age 4/5 and 8/10 years and nitrogen oxides $\left(\mathrm{NO}_{x}\right)$ at the birth, age $4 / 5$ and age $8 / 10$ years addresses. Associations shown were derived from the adjusted model (model 2). Odds ratios are reported per $20 \mu \mathrm{g} \cdot \mathrm{m}^{-3} \mathrm{NO}_{x}$. PIAMA: Prevention and Incidence of Asthma and Mite Allergy; MAAS: Manchester Asthma and Allergy Study; GINI: German Infant Nutritional Intervention; LISA: Lifestyle-Related Factors on the Development of the Immune System and Allergic Disease; BAMSE: Barn Allergi Miliö Stockholm Epidemiologi.

\section{Description of exposures}

A summary of the pollutant exposures is shown in table 3. Mean exposures at the age 4 and 8 years addresses were similar to exposures at birth. The mean $\mathrm{NO}_{2}, \mathrm{NO}_{x}$ and $\mathrm{PM} 2.5$ absorbance exposures in BAMSE were lower than in other cohorts. The mean exposures to PM10 and PM2.5 in MAAS and BAMSE were lower than the mean exposures in PIAMA and GINI/LISA. However, the mean exposure to coarse particulate matter was similar across all cohorts, indicating that the difference between PM10 and PM2.5 exposure was similar in all study areas. The ranges of exposures in MAAS were smaller than in the other cohorts, possibly due to differences in urban layout between the UK and the other study areas. We also note, however, that the geographic area within Manchester from which the MAAS cohort was recruited was smaller than the study areas in the other countries. The back-extrapolated exposure estimates for the birth addresses were strongly correlated with the original exposure estimates for the birth addresses (Pearson's $r=0.56-0.99$ ). The correlation between all exposure variables is shown in tables S3-S7.

\section{Pollution exposure and asthma prevalence}

The results of the meta-analyses (crude and adjusted models) of the association between asthma prevalence and pollutant exposure are shown in table 4. With the exception of PM10, the pollutants studied showed positive associations with asthma prevalence in the adjusted analyses but were not statistically significant, and therefore the null hypothesis (of no effect) could not be rejected. Analyses of nitric oxides displayed significant heterogeneity. Forest plots of the adjusted association (model 2) between asthma prevalence and pollutant exposure in individual cohorts are shown in figures 2-7. Figure 2 shows that $\mathrm{NO}_{2}$ exposure at birth significantly increased the odds of asthma prevalence at age 8 years in the PIAMA and MAAS cohorts; however, overall $\mathrm{NO}_{2}$ exposure at birth, or age 4 or age 8 years showed no significant association with asthma prevalence at age 4 or 8 years. As shown in table S8, there was little association between traffic metrics and asthma prevalence. The results of further analyses (models 3-7) are 




FIGURE 4 Forest plot of the association between asthma at age $4 / 5$ and $8 / 10$ years and particulate matter with an aerodynamic diameter $<2.5 \mu$ m $($ PM2.5) at the birth, age 4/5 and age 8/10 years addresses. Associations shown were derived from the adjusted model (model 2 ). Odds ratios are reported per $5 \mu$ g.m ${ }^{-3}$ PM2.5.

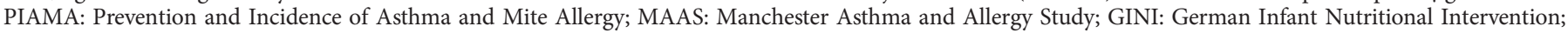
LISA: Lifestyle-Related Factors on the Development of the Immune System and Allergic Disease; BAMSE: Barn Allergi Miliö Stockholm Epidemiologi.

shown in table S9. In general, these further analyses showed no significant association between asthma prevalence and the traffic-related air pollutants included in this study.

The results of the multinomial logistic regression analyses are shown in table S10. None of these analyses showed a significant association between nonatopic asthma or atopic asthma at age 8/10 years and the assessed air pollution metrics.

\section{Pollution exposure and "current" wheeze prevalence}

The results of the meta-analyses (crude and adjusted models) of the associations between current wheeze prevalence and pollutant exposures are shown in table S11. Forest plots of the adjusted association (model 2) between current wheeze prevalence and pollutant exposure in individual cohorts are shown in figure S1. None of the meta-analyses showed a significant association between current wheeze prevalence at age 4 or 8 years and pollutant exposure at the birth, age 4 or age 8 years addresses. The results of further analyses (models 3-7) are shown in table S12. In general, these further analyses showed no significant association between current wheeze prevalence and the air pollution metrics.

\section{Discussion}

This large collective study of five European birth cohorts $(n=7096-11555)$ used a harmonised approach to assess exposure to traffic-related air pollutants and relate them to the prevalence of asthma or current wheeze during childhood. Overall, this study found no evidence of a significant association between the selected particulate and $\mathrm{NO}_{x}$ air pollution exposure metrics and the prevalence of asthma or current wheeze during childhood.

The main strength of this study was its harmonised approach to study design, health assessment, exposure assessment and statistical analysis. The five birth cohorts included in this study were specifically designed to study the development of asthma and allergy during childhood. Recruitment in all cohorts took place 


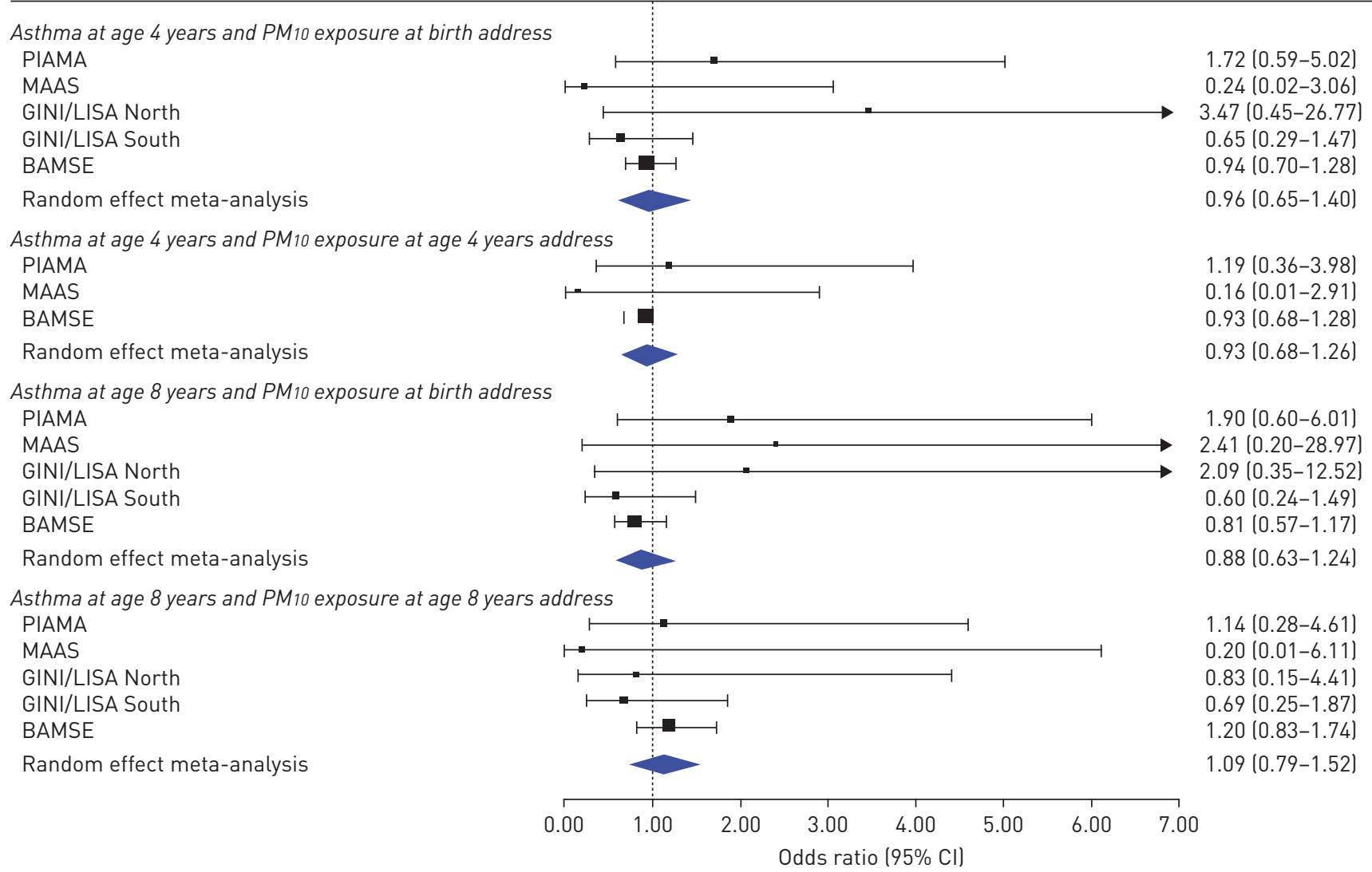

FIGURE 5 Forest plot of the association between asthma at age $4 / 5$ and $8 / 10$ years and particulate matter with an aerodynamic diameter $<10 \mu \mathrm{m}(\mathrm{PM} 10)$ at the birth, age 4/5 and age 8/10 years addresses. Associations shown were derived from the adjusted model (model 2). Odds ratios are reported per $10 \mu \mathrm{g} \cdot \mathrm{m}^{-3} \mathrm{PM} 10$. PIAMA: Prevention and Incidence of Asthma and Mite Allergy; MAAS: Manchester Asthma and Allergy Study; GINI: German Infant Nutritional Intervention; LISA: Lifestyle-Related Factors on the Development of the Immune System and Allergic Disease; BAMSE: Barn Allergi Miliö Stockholm Epidemiologi.

between 1994 and 1999. All cohorts used the ISAAC questionnaire to collect information on asthma and current wheeze prevalence. In addition, the same definition of asthma was used by all cohorts, based on the GA ${ }^{2} L E N$ approach of two out of three positive variables, which is thought to reduce misclassification of childhood asthma [26, 27]. All cohorts used the same harmonised exposure assessment method, including dedicated monitoring campaigns and area specific LUR models.

A limitation of this study was that the LUR models were based on measurement campaigns carried out in 2009, but the exposure time-points specified were between 1994 and 2008. Several studies have investigated the validity of using LUR models developed from current data to estimate exposure in the previous 10-15 years, by comparing modelled to measured data: a study in the Netherlands found that a LUR model developed from 2007 data could explain 77\% of the variability in concentrations measured in 1999-2000 [36]; a similar study in Rome, Italy, found that a LUR model developed from 2007 data could explain $83 \%$ of the variability in $\mathrm{NO}_{2}$ concentrations measured in 1995-1996 [37]; while a study in Vancouver, Canada, found that a model developed from 2010 data could explain $63 \%$ of the variability in $\mathrm{NO}_{2}$ concentrations measured in 2003 [38]. The results of these studies indicate that models developed from 2009 data can be a valid tool to estimate the spatial variation of pollutant concentrations at earlier time points, e.g. at the birth of the children. Moreover, a sensitivity of analyses of the logistic regression models using back-extrapolated $\mathrm{NO}_{2}, \mathrm{NO}_{x}$ and PM10 concentrations provided similar results as the models using exposure at the birth address (model 5, tables S9 and S12). However, further tests in other study areas to confirm these findings would be beneficial.

A further limitation of this study was that it only analysed outdoor air pollution exposure. Indoor exposures may differ from outdoor exposures, but it was not feasible to measure or reliably estimate indoor exposure individually for each of $>10000$ children in this multicentre study. For the same reason, measurement of personal exposure to outdoor air pollution was also not possible. Exposure misclassification is a common limitation in air pollution epidemiology and recent research has 


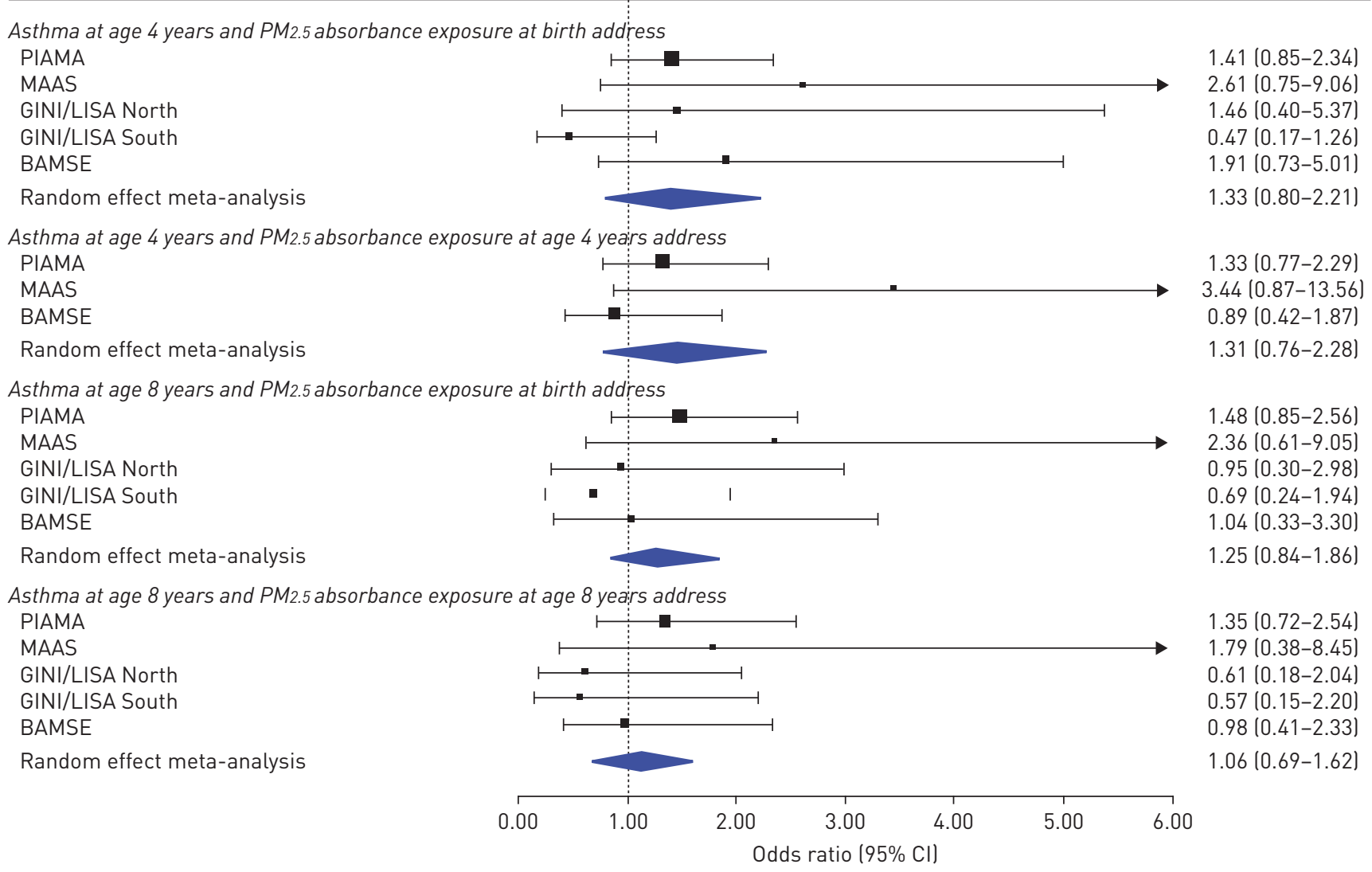

FIGURE 6 Forest plot of the association between asthma at age 4/5 and 8/10 years and particulate matter with an aerodynamic diameter $<2.5 \mu$ m $($ PM2.5) absorbance at the birth, age 4/5 and age 8/10 years addresses. Associations shown were derived from the adjusted model (model 2). Odds ratios are reported per $10^{-5} \mathrm{~m}^{-1}$ PM2.5 absorbance. PIAMA: Prevention and Incidence of Asthma and Mite Allergy; MAAS: Manchester Asthma and Allergy Study; GINI: German Infant Nutritional Intervention; LISA: Lifestyle-Related Factors on the Development of the Immune System and Allergic Disease; BAMSE: Barn Allergi Miliö Stockholm Epidemiologi.

demonstrated that measurement errors can bias health effect estimates [39]. To minimise its impact in this study, exposure models were used that have been extensively evaluated in previous publications [17, 19, 40] and their performance was found to be acceptable. In addition, a recent study in Utrecht (the Netherlands), Helsinki (Finland) and Barcelona (Spain) compared pollutant estimates from the ESCAPE LUR models against measurements from personal monitors [41]. In a pooled analysis, this study found high coefficients of determination between modelled and measured concentrations of PM2.5 absorbance $\left(\mathrm{r}^{2}=0.83\right), \mathrm{NO}_{2}\left(\mathrm{r}^{2}=0.79\right)$ and $\mathrm{NO}_{x}\left(\mathrm{r}^{2}=0.54\right)$.

The large number of confounders adjusted for in the statistical model may have led to over-adjustment and to statistical models that were overly conservative. However, the crude models (table 5 and table S8) did not show a positive association between the air pollution experienced and asthma or wheeze prevalence; hence, it is unlikely that the confounder selection had an undue influence on the findings of this study.

Previous research has suggested critical windows of exposure, in particular infancy, that could lead to health effects later in life [42]. Due to the fact that none of the meta-analyses showed a significant association between asthma prevalence and exposure, our study did not provide any further insight into this issue. However, at age 4 years, a number of effect estimates for individual cohorts displayed significant heterogeneity, but this heterogeneity decreased with increasing age of the children (table 5 and table S8). This may suggest differences in susceptibility between cohorts at a younger age, which attenuated over time. The heterogeneity during early life also highlights that even though this study was designed to ensure a high degree of homogeneity in the methodology, further underlying differences between individual cohorts may exist. For example, differences in the chemical composition of PM10, PM2.5 and coarse PM between study areas [43] could lead to different effects within the cohorts. To account for potential heterogeneity, we concluded that the best approach was to carry out a random-effects meta-analysis as opposed to a fixed-effects meta-analysis or a pooled analysis. However, within-area correlations were relatively low. This may be relevant 


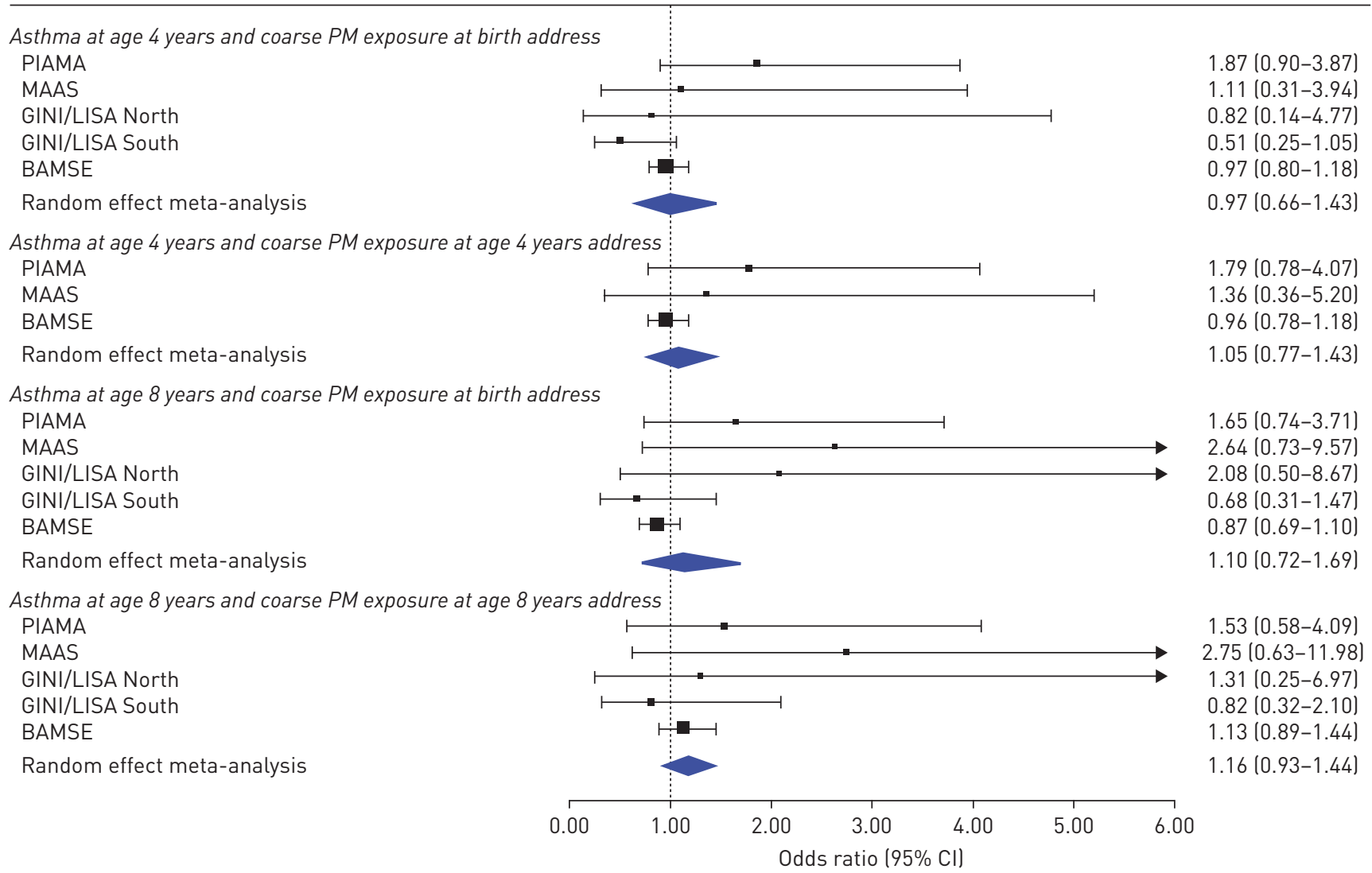

FIGURE 7 Forest plot of the association between asthma at age 4/5 and 8/10 years and coarse particulate (PM) absorbance at the birth, age 4/5 and age 8/10 years addresses. Associations shown were derived from the adjusted model (model 2). Odds ratios are reported per $5 \mu$ g. ${ }^{-3}$ coarse PM. PIAMA: Prevention


Lifestyle-Related Factors on the Development of the Immune System and Allergic Disease; BAMSE: Barn Allergi Miliö Stockholm Epidemiologi.

because our analyses of asthma and wheeze were within-area and not pooled. As a consequence, misclassification of personal exposure may partly explain the nonsignificant findings in our study.

A small number of meta-analyses and multinational studies have been published on childhood asthma prevalence and air pollution exposure [44-49]. A meta-analysis of published studies reported a borderline-significant increase in asthma prevalence associated with $\mathrm{NO}_{2}$ or $\mathrm{NO}_{x}$ exposure [49]. However, no significant association was found between asthma prevalence and PM10 or PM2.5 exposure or wheeze prevalence and $\mathrm{NO}_{2}$ or particulate matter exposure [49]. A recent meta-analysis of multicommunity studies found no evidence of an association between community levels of $\mathrm{NO}_{2}$ or $\mathrm{PM} 10$ concentrations and asthma prevalence in children [47]. Unlike the above studies, which were based on published work, a recent study in the US carried out a meta-analysis of original results from logistic regression analyses within five regions in mainland USA and Puerto Rico [47]. Within each region, a frequency-matched case-control design was used to analyse the association between asthma and $\mathrm{NO}_{2}, \mathrm{PM}_{10}$ and PM2.5 in Latin and African American children and adolescents (age range 8-21 years). The pooled effect estimates showed a statistically significant association between asthma and $\mathrm{NO}_{2}$ exposure during the first year of life, but no significant association with PM10 or PM2.5 exposure. The mean $\mathrm{NO}_{2}$ (9.9-26.9 ppb) and $\mathrm{PM}_{10}$ (24.5-34.1 $\left.\mu \mathrm{g} \cdot \mathrm{m}^{-3}\right)$ concentrations across the five regions were higher than the mean concentrations in our study areas (table 3); however, the mean PM2.5 (8.1-17.0 $\mu \mathrm{g} \cdot \mathrm{m}^{-3}$ ) concentrations were comparable to our study areas. This could indicate that differences in findings between their study and our study were related to pollutant levels rather than ethnicity, but further research would be required to confirm this. The Pollution and the Young (PATY) study meta-analysed original results from cross-sectional studies conducted in 12 European countries between 1993 and 1999 [44, 45]. Each cross-sectional study included in the analysis collected information on asthma and current wheeze prevalence via parental questionnaires and $\mathrm{NO}_{2}$ and PM10 exposure data measured at a central monitoring station. Similar to our study, the pooled effect estimates showed no association between air pollution exposure and asthma or wheeze prevalence. An ecological study compared data on asthma and wheeze prevalence collected during phase 1 
of ISAAC with city-level estimates of residential PM10 provided by a World Bank model [46]. The results of this study suggested that urban background concentrations of PM10 have little or no association with childhood asthma prevalence.

In addition to the above meta-analyses and multinational studies, a number of cohort studies have investigated the association between asthma prevalence and air pollution exposure. As described in the introduction, results from these studies have been heterogeneous [2-13]. For example, the Children's Health Study, based in California, USA, found an association between $\mathrm{NO}_{2}$ exposure and asthma prevalence [4], while the Environment and Childhood Asthma study based in Oslo, Norway, found no association [9]. Furthermore, the five cohorts in our study have previously published individual findings in their cohorts $[6-8,12,13]$. As described in the introduction, differences in methodology and especially in exposure assessment may explain some of the discrepancies in results. In addition, study area-specific factors could also lead to different findings. However, we would like to reiterate that the aim of our study was a harmonised multinational analysis to provide a "bigger picture" view of childhood asthma prevalence and air pollution, rather than a comparison of findings from individual cohorts.

In conclusion, our study has found no significant association between exposure to selected air pollution metrics and childhood asthma in a meta-analysis of five birth cohorts located in in five large conurbations in Europe, although effect estimates for five out of the six pollutant metrics and asthma were positive. Importantly these conurbations displayed asthma prevalence rates and exposure ranges typical of those found in many European countries, rendering the results likely to be broadly applicable within similarly exposed children in Europe. Exposure to traffic-related air pollution was modelled for each of the $>11000$ children using identical exposure assessment methods and the definition of asthma was assigned using answers to the same questions from the same questionnaire. Considering the scale of this study and its degree of harmonisation, it provides important new findings on the effect of air pollution exposure over the last 10-15 years on childhood asthma prevalence in major urban areas in north, west and central Europe, although other conurbations not studied here might have experienced higher pollutant concentrations. We emphasise that there are many aspects of the complex association between childhood asthma and air pollution exposure that this study did not address, which merit further study. For example, the effect of long-term air pollution exposure on asthma exacerbations in patients with pre-existing asthma was not addressed, but previous research has suggested an association [1]. Furthermore, the impact of indoor air pollution concentrations or air pollution concentrations in transport environments on childhood asthma was not included in this study, but should be addressed further. In addition, the inclusion of genetic data in further analyses may provide useful insight into potential gene-environment interactions and might identify individuals or endotypes associated with particular risk. Finally, the lack of a significant association between childhood asthma prevalence and air pollution exposure does not prove that air pollution exposure has no effect on children's respiratory health.

\section{Acknowledgements}

The authors' affiliations are as follows. Anna Mölter: Centre for Occupational and Environmental Health, Centre for Epidemiology, Institute of Population Health, Manchester Academic Health Sciences Centre, University of Manchester, Manchester, UK, and Dept of Environmental and Radiological Health Sciences, Colorado State University, Fort Collins, CO, USA; Angela Simpson: Centre for Respiratory and Allergy, Institute of Inflammation and Repair, Manchester Academic Health Sciences Centre, University of Manchester, University Hospital of South Manchester NHS Foundation Trust, Manchester, UK; Dietrich Berdel: Marien-Hospital Wesel, Research Institute, Dept of Pediatrics, Wesel, Germany; Bert Brunekreef: Institute for Risk Assessment Sciences, Utrecht University, and Julius Center for Health Sciences and Primary Care, University Medical Center Utrecht, Utrecht, The Netherlands; Adnan Custovic: Centre for Respiratory and Allergy, Institute of Inflammation and Repair, Manchester Academic Health Sciences Centre, University of Manchester, University Hospital of South Manchester NHS Foundation Trust, Manchester, UK; Josef Cyrys: Helmholtz Zentrum München, German Research Center for Environmental Health, Institute of Epidemiology II, Neuherberg, Germany; Johan de Jongste: Dept of Pediatrics, Division of Respiratory Medicine, Erasmus University Medical Center/ Sophia Children's Hospital, Rotterdam, The Netherlands; Frank de Vocht: Centre for Occupational and Environmental Health, Centre for Epidemiology, Institute of Population Health, Manchester Academic Health Sciences Centre, University of Manchester, Manchester, UK; Elaine Fuertes: Helmholtz Zentrum München, German Research Center for Environmental Health, Institute of Epidemiology I, Neuherberg, Germany; Ulrike Gehring: Institute for Risk Assessment Sciences, Utrecht University, Utrecht, The Netherlands; Olena Gruzieva: Institute of Environmental Medicine, Karolinska Institutet, Stockholm, Sweden; Joachim Heinrich: Helmholtz Zentrum München, German Research Center for Environmental Health, Institute of Epidemiology I, Neuherberg, Germany; Gerard Hoek: Institute for Risk Assessment Sciences, Utrecht University, Utrecht, The Netherlands; Barbara Hoffmann: IUF-Leibniz Research Institute for Environmental Medicine at the University of Dusseldorf, and Medical Faculty, Heinrich-Heine-University Dusseldorf, Dusseldorf, Germany; Claudia Klümper: IUF-Leibniz Research Institute for Environmental Medicine at the University of Dusseldorf, Dusseldorf, Germany; Michal Korek: Institute of Environmental Medicine, Karolinska Institutet, Stockholm, Sweden; Thomas A.J. Kuhlbusch: Air Quality and Sustainable Nanotechnology, Institut für Energie- und Umwelttechnik (IUTA) e.V., Duisburg, and Centre for Nanointegration CENIDE, University of Duisburg-Essen, Essen, Germany; Sarah Lindley: School of Environment, Education and Development (Geography), University of Manchester, Manchester, UK; Dirkje Postma: Dept of Pulmonary Medicine and Tuberculosis, University Medical Center Groningen, Groningen, The Netherlands; Christina Tischer: Helmholtz Zentrum München, German 
Research Center for Environmental Health, Institute of Epidemiology I, Neuherberg, Germany; Alet Wijga: Center for Nutrition, Prevention and Health Services, National Institute for Public Health and the Environment, Bilthoven, The Netherlands; Göran Pershagen: Institute of Environmental Medicine, Karolinska Institutet, Stockholm, Sweden; Raymond Agius: Centre for Occupational and Environmental Health, Centre for Epidemiology, Institute of Population Health, Manchester Academic Health Sciences Centre, University of Manchester, Manchester, UK.

We would like to thank all families participating in the MAAS, BAMSE, PIAMA, GINIplus and LISAplus cohort studies, and the respective study teams for their hard work and effort.

\section{References}

1 Kunzli N, Kaiser R, Medina S, et al. Public-health impact of outdoor and traffic-related air pollution: a European assessment. Lancet 2000; 356: 795-801.

2 Brauer M, Hoek G, Smit HA, et al. Air pollution and development of asthma, allergy and infections in a birth cohort. Eur Respir J 2007; 29: 879-888.

3 Brauer M, Hoek G, van Vliet P, et al. Air pollution from traffic and the development of respiratory infections and asthmatic and allergic symptoms in children. Am J Respir Crit Care Med 2002; 166: 1092-1098.

4 Gauderman WJ, Avol E, Lurmann F, et al. Childhood asthma and exposure to traffic and nitrogen dioxide Epidemiology 2005; 16: 737-743.

5 Gehring U, Cyrys J, Sedlmeir G, et al. Traffic-related air pollution and respiratory health during the first 2 yrs of life. Eur Respir J 2002; 19: 690-698.

6 Gehring U, Wijga AH, Brauer M, et al. Traffic-related air pollution and the development of asthma and allergies during the first 8 years of life. Am J Respir Crit Care Med 2010; 181: 596-603.

7 Kramer U, Sugiri D, Ranft U, et al. Eczema, respiratory allergies, and traffic-related air pollution in birth cohorts from small-town areas. J Dermatol Sci 2009; 56: 99-105.

8 Morgenstern V, Zutavern A, Cyrys J, et al. Respiratory health and individual estimated exposure to traffic-related air pollutants in a cohort of young children. Occup Environ Med 2007; 64: 8-16.

9 Oftedal B, Nystad W, Brunekreef B, et al. Long-term traffic-related exposures and asthma onset in school children in Oslo, Norway. Environ Health Perspect 2009; 117: 839-844.

10 Shima M. Effects of air pollution on the prevalence and incidence of asthma in children. Arch Environ Health 2002; 57: 529-535

11 Shima M, Adachi M. Effect of outdoor and indoor nitrogen dioxide on respiratory symptoms in school children Int J Epidemiol 2000; 29: 862-870.

12 Gruzieva O, Bergstrom A, Hulchiy O, et al. Exposure to air pollution from traffic and childhood asthma until 12 years of age. Epidemiology 2013; 24: 54-61.

13 Mölter A, Agius R, de Vocht F, et al. Effects of long-term exposure to $\mathrm{PM}_{10}$ and $\mathrm{NO}_{2}$ on asthma and wheeze in a prospective birth cohort. J Epidemiol Community Health 2014; 68: 21-28.

14 Van Wonderen KE, Van Der Mark LB, Mohrs J, et al. Different definitions in childhood asthma: how dependable is the dependent variable?. Eur Respir J 2010; 36: 48-56.

15 Braback L, Forsberg B. Does traffic exhaust contribute to the development of asthma and allergic sensitization in children: findings from recent cohort studies. Environ Health 2009; 8: 17-28.

16 HEI Panel on the Health Effects of Traffic-Related Air Pollution. Traffic-Related Air Pollution: A Critical Review of the Literature on Emissions, Exposure, and Heath Effects. Boston, Health Effects Institute, 2010.

17 Beelen $\mathrm{R}$, Hoek G, Vienneau D, et al. Development of $\mathrm{NO}_{2}$ and $\mathrm{NO}_{x}$ land use regression models for estimating air pollution exposure in 36 study areas in Europe - the ESCAPE project. Atmos Environ 2013; 72: 10-23.

18 Cyrys J, Eeftens $\mathrm{M}$, Heinrich J, et al. Variation of $\mathrm{NO}_{2}$ and $\mathrm{NO}_{x}$ concentrations between and within 36 European study areas: results from the ESCAPE study. Atmos Environ 2012; 62: 374-390.

19 Eeftens M, Beelen R, de Hoogh K, et al. Development of land use regression models for PM2.5, PM2.5 absorbance, PM10 and $\mathrm{PM}_{\text {coarse }}$ in 20 European study areas; results of the ESCAPE project. Environ Sci Technol 2012; 46: 11195-11205.

20 Eeftens M, Tsai MY, Ampe C, et al. Spatial variation of PM2.5, PM10, PM2.5 absorbance and PMcoarse concentrations between and within 20 European study areas and the relationship with $\mathrm{NO}_{2}-$ results of the ESCAPE project. Atmos Environ 2012; 62: 303-317.

21 Brunekreef B, Holgate ST. Air pollution and health. Lancet 2002; 360: 1233-1242.

22 Custovic A, Simpson BM, Murray CS, et al. The National Asthma Campaign Manchester Asthma and Allergy Study. Pediatr Allergy Immunol 2002; 13: 32-37.

23 Keil T, Kulig M, Simpson A, et al. European birth cohort studies on asthma and atopic diseases: II. Comparison of outcomes and exposures - a GA2 LEN initiative. Allergy 2006; 61: 1104-1111.

24 Wickman M, Kull I, Pershagen G, et al. The BAMSE project: presentation of a prospective longitudinal birth cohort study. Pediatr Allergy Immunol 2002; 13 Suppl. 15: 11-13.

25 Asher MI, Keil U, Anderson HR, et al. International Study of Asthma and Allergies in Childhood (ISAAC): rationale and methods. Eur Respir J 1995; 8: 483-491.

26 Carlsen KCL, Håland G, Devulapalli CS, et al. Asthma in every fifth child in Oslo, Norway: a 10-year follow up of a birth cohort study. Allergy 2006; 61: 454-460.

27 Haland G, Carlsen KCL, Sandvik L, et al. Reduced lung function at birth and the risk of asthma at 10 years of age. N Engl J Med 2006; 355: 1682-1689.

28 ESCAPE. Exposure Assessment Manual. www.escapeproject.eu/manuals/ESCAPE_Exposure-manualv9.pdf Date last updated: July 2010.

29 Beelen R, Stafoggia M, Raaschou-Nielsen O, et al. Long-term exposure to air pollution and cardiovascular mortality: an analysis of 22 European cohorts. Epidemiology 2014; 25: 368-378.

30 ESCAPE. Procedure for extrapolation back in time. www.escapeproject.eu/manuals/Procedure_for_extrapolation back_in_time.pdf Date last updated: January 25, 2012.

31 Kirkwood B, Sterne J. Essential Medical Statistics. Hoboken, Blackwell Science Ltd, 2003

32 DerSimonian R, Laird N. Meta-analysis in clinical trials. Control Clin Trials 1986; 7: 177-188. 

Statistical Computing, 2012.

34 Fischer PH, Hoek G, van Reeuwijk H, et al. Traffic-related differences in outdoor and indoor concentrations of particles and volatile organic compounds in Amsterdam. Atmos Environ 2000; 34: 3713-3722.

35 Janssen NAH, van Vliet PHN, Aarts F, et al. Assessment of exposure to traffic related air pollution of children attending schools near motorways. Atmos Environ 2001; 35: 3875-3884.

36 Eeftens M, Beelen R, Fischer $\mathrm{P}$, et al. Stability of measured and modelled spatial contrasts in $\mathrm{NO}_{2}$ over time. Occup Environ Med 2011; 68: 765-770.

37 Cesaroni G, Porta D, Badaloni C, et al. Nitrogen dioxide levels estimated from land use regression models several years apart and association with mortality in a large cohort study. Environ Health 2012; 11: 48.

38 Wang R, Henderson SB, Sbihi $\mathrm{H}$, et al. Temporal stability of land use regression models for traffic-related air pollution. Atmos Environ 2012; 64: 312-319.

39 Basagaña X, Aguilera I, Rivera M, et al. Measurement error in epidemiologic studies of air pollution based on land-use regression models. Am J Epidemiol 2013; 178: 1342-1346.

40 Wang M, Beelen R, Basagana X, et al. Evaluation of land use regression models for $\mathrm{NO}_{2}$ and particulate matter in 20 European study areas: the ESCAPE project. Environ Sci Technol 2013; 47: 4357-4364.

41 Montagne D, Hoek G, Nieuwenhuijsen M, et al. Agreement of land use regression models with personal exposure measurements of particulate matter and nitrogen oxides air pollution. Environ Sci Technol 2013; 47: 8523-8531.

42 Dietert RR, Etzel RA, Chen D, et al. Workshop to identify critical windows of exposure for children's health: immune and respiratory systems work group summary. Environ Health Perspect 2000; 108 Suppl. 3: 483-490.

43 Putaud JP, Van Dingenen R, Alastuey A, et al. European aerosol phenomenology - 3: physical and chemical characteristics of particulate matter from 60 rural, urban, and kerbside sites across Europe. Atmos Environ 2010; 44: $1308-1320$.

44 Hoek G, Pattenden S, Willers S, et al. PM10 and children's respiratory symptoms and lung function in the PATY study. Eur Respir J 2012; 40: 538-547.

45 Pattenden S, Hoek G, Braun-Fahrländer C, et al. $\mathrm{NO}_{2}$ and children's respiratory symptoms in the PATY study. Occup Environ Med 2006; 63: 828-835.

46 Anderson HR, Ruggles R, Pandey KD, et al. Ambient particulate pollution and the world-wide prevalence of asthma, rhinoconjunctivitis and eczema in children: phase one of the International Study of Asthma and Allergies in Childhood (ISAAC). Occup Environ Med 2010; 67: 293-300.

47 Anderson HR, Favarato G, Atkinson R. Long-term exposure to outdoor air pollution and the prevalence of asthma: meta-analysis of multi-community prevalence studies. Air Qual Atmos Health 2013; 6: 57-68.

48 Nishimura KK, Galanter JM, Roth LA, et al. Early life air pollution and asthma risk in minority children: the GALA II \& SAGE II studies. Am J Respir Crit Care Med 2013; 188: 309-318.

49 Gasana J, Dillikar D, Mendy A, et al. Motor vehicle air pollution and asthma in children: a meta-analysis. Environ Res 2012; 117: 36-45. 